\title{
First pregnancy events and future breast density: modification by age at first pregnancy and specific VEGF and IGF1R gene variants
}

\author{
Lee Ann Prebil • Rochelle R. Ereman • Mark J. Powell • \\ Farid Jamshidian · Karla Kerlikowske • John A. Shepherd • \\ Marc S. Hurlbert · Christopher C. Benz
}

Received: 18 October 2013/Accepted: 12 April 2014/Published online: 7 May 2014

(C) The Author(s) 2014. This article is published with open access at Springerlink.com

\begin{abstract}
Purpose Pregnancy characteristics have been associated with breast cancer risk, but information is limited on their relationship with breast density. Our objective was to examine the relationship between first pregnancy characteristics and later life breast density, and whether the association is modified by genotype.

Methods The Marin Women's Study was initiated to examine breast cancer in a high-incidence mammography population (Marin County, CA). Reproductive characteristics and pregnancy information including pregnancyinduced hypertension (PIH) were self-reported at the time
\end{abstract}

Electronic supplementary material The online version of this article (doi:10.1007/s10552-014-0386-2) contains supplementary material, which is available to authorized users.

L. A. Prebil $(\varangle)$ · R. R. Ereman · M. J. Powell · F. Jamshidian Marin County Department of Health and Human Services, 899 Northgate Drive, Suite 415, San Rafael, CA 94903, USA

e-mail: 1prebil@cal.berkeley.edu

K. Kerlikowske

Departments of Medicine and Epidemiology and Biostatistics, University of California, San Francisco, CA, USA

J. A. Shepherd

Department of Radiology and Biomedical Imaging, University of California, San Francisco, CA, USA

M. S. Hurlbert

Avon Foundation for Women, New York, NY, USA

C. C. Benz

Buck Institute for Research on Aging, Novato, CA, USA

C. C. Benz

Helen Diller Family Comprehensive Cancer Center, University of California, San Francisco, CA, USA of mammography. Forty-seven candidate single nucleotide polymorphisms were obtained from saliva samples; seven were assessed in relation to $\mathrm{PIH}$ and percent fibroglandular volume (\%FGV). Breast density assessed as \%FGV was measured on full-field digital mammograms by the San Francisco Mammography Registry.

Results A multivariable regression model including 2,440 parous women showed that PIH during first pregnancy was associated with a statistically significant decrease in \%FGV ( $b=-0.31,95 \% \mathrm{CI}-0.52,-0.11)$, while each month of breast-feeding after first birth was associated with a statistically significant increase in \% FGV $(b=0.01,95 \% \mathrm{CI}$ $0.003,0.02)$. PIH and breast-feeding associations with $\%$ FGV were modified by age at first birth. In a subsample of 1,240 women, there was evidence of modification in the association between PIH and \%FGV by specific vascular endothelial growth factor (VEGF) (rs3025039) and insulin growth factor receptor-1 (IGFR1) (rs2016347) gene variants.

Conclusion These findings suggest that first pregnancy characteristics may exert an influence on extent of breast density later in life and that this influence may vary depending on inherited IGFR1 and VEGF genotypes.

Keywords Breast density - Breast cancer - Pregnancy . Pregnancy-induced hypertension $\cdot$ SNPs $\cdot$ Reproductive history
Abbreviations
$\%$ FGV Percent fibroglandular volume
MWS Marin Women's Study
SNPs Single nucleotide polymorphisms
PIH Pregnancy-induced hypertension
SFMR San Francisco Mammography Registry
SXA Single X-ray absorptiometry 
IGFR1 Insulin growth factor receptor-1

VEGF-A Vascular endothelial growth factor-A

\section{Background}

Parity and age at first birth consistently have been shown to be associated with breast cancer risk in women worldwide (e.g., [1]). The mechanisms underlying the protective effect of pregnancy include a reduction in the number of mammary stem cells, an alteration in the responsiveness of the breast to estrogens, differentiation of mammary epithelial cells, and a change in the levels of circulating hormones (as reviewed in [2]). In addition to the difference in breast cancer risk between nulliparous and parous women, there is evidence that the characteristics of pregnancy, particularly first birth, affect breast cancer risk. An increased risk of breast cancer has been associated with having had a pregnancy that resulted in a preterm birth [3], higher birthweight (e.g., [4]), or multifetal gestation [3], and a decreased risk has been found with having had a pregnancy in which the woman developed hypertension or preeclampsia [3, 5], had a smaller placental weight [6], or had nausea or vomiting [7, 8]. Investigators have found that pregnancy characteristics may be particularly important in the first birth, and with a late age at first birth (e.g., [3]).

The relationship between pregnancy characteristics and breast density has received little attention. Breast density has an established, strong relationship to breast cancer. Research has suggested that this relationship is causal rather than correlational (e.g., [9]) thus providing a potentially important surrogate target for prevention studies. While research has consistently shown a negative association between increasing parity and breast density (e.g., $[10,11]$ ), findings have been less consistent for an association between breast density and older age at first birth (as reviewed in [12]). A few studies have demonstrated that some of the same birth characteristics shown to be associated with increased breast cancer risk were associated with high breast density, specifically, preterm birth, nulliparity/low parity, older age at first birth, and high birth weight [10, 11, 13, 14]. Lope et al. [14] found that duration of breastfeeding was positively associated with breast density, while Butler et al. [10] found no significant association between breast-feeding and breast density.

A better understanding of the association between first pregnancy and breast density could inform breast cancer prevention efforts. If first birth characteristics are found to be associated with breast density in the same direction as their association with breast cancer, this would indicate that these pregnancy events affect breast cancer through their impact on breast density. This study therefore aimed to examine the association between first pregnancy and breast density (Study 1). We additionally endeavored to further explore whether the association between first pregnancy and breast density varied by candidate germline gene variants, specifically single nucleotide polymorphisms (SNPs) known to be related to breast cancer, breast density, or pregnancy characteristics (Study 2).

\section{Materials and methods}

\section{Study participants}

This study was conducted using data from women enrolled in the Marin Women's Study (MWS). The MWS is a crosssectional study conducted at mammography centers in Marin County, California associated with Kaiser Permanente, Sutter Health (Novato Community Hospital), and Marin General Hospital. It is estimated that $80 \%$ of mammograms conducted in Marin residents are conducted at centers affiliated with these health care facilities, representing approximately 38,000 women annually. These mammography sites are also included in the San Francisco Mammography Registry (SFMR), one of seven registries included in the National Cancer Institute Breast Cancer Surveillance Consortium. Risk factors and saliva specimens collected in the MWS are linked with breast density, measured as percent fibroglandular volume (\%FGV), and breast cancer outcome.

At the time of analysis, there were 11,361 women enrolled in the MWS; for purposes of this analysis (Study $1)$, women were excluded if they were missing data on age $(n=80)$, if they reported ever having been diagnosed with breast cancer $(n=751)$, if they reported taking antiestrogens $(n=107)$, if they had never had a live birth $(n=2,814)$, if they did not have a measure of breast density assessed as \%FGV $(n=4,326)$, if they had missing data on any of the model variables $(n=639)$, if they reported having had a hysterectomy with ovarectomy $(n=160)$, or if their first birth was not a singleton birth $(n=44)$, leaving an analysis population of 2,440 .

\section{Exposure assessment}

Primary data collection in the MWS includes self-report information from a questionnaire. Women are asked to report in-depth information on their reproductive history, including information on life course socioeconomic status, alcohol use, and use of exogenous hormones, and data on other established breast cancer risk factors, including family history. Reproductive history includes parity and age at first birth, and for each pregnancy women are asked to report multifetal gestation, duration of breast-feeding, 
low and high birth weight $(<2,500 \mathrm{~g},>4,000 \mathrm{~g})$, preterm birth, pregnancy weight gain (pounds), and high blood pressure during pregnancy [or pregnancy-induced hypertension (PIH)] (yes/no). Self-reported height and weight are collected from the SFMR.

At the time of entry into the MWS, women are asked whether they are willing to donate a saliva specimen. Those who consent to donate a saliva sample ( $89 \%$ of population) are sent a kit in the mail and asked to return the tube of donated saliva in a preaddressed and postage-paid envelope to the Buck Institute for Research on Aging where the saliva is logged, stored, and processed. The specimens are processed by separation into supernatant available for steroid hormone analysis, and a cellular component from which DNA is isolated using Invitrogen's PureLink Genomic DNA kits. Samples are stored in the MWS Biorepository housed at the Buck Institute in Novato, California.

\section{Selection of SNP candidates}

For Study 2, participants were also selected from the MWS population and were drawn from among 2,400 participants for whom SNP data were available from donated saliva samples.

Twenty-five preselected candidate SNPs were multiplexed and analyzed in the MWS DNA samples by InterGenetics, Inc (Oklahoma City, OK) in parallel with analysis of their panel of 22 OncoVue SNPs. All SNP assays were performed and evaluated as previously described [15], and the CLIAapproved 22 SNP OncoVue assay and algorithm were previously validated as a new individualized breast cancer risk estimator using buccal DNA samples from an earlier (1997-1999) Marin County case-control study cohort [16]. Selection of the novel 25 SNP candidates evaluated in the present study followed a detailed literature search of SNPs reported in GWAS studies to be significantly associated (in at least one published report) to specific exposures, outcomes, and hypothesized breast cancer associated pathways of relevance to the current MWS. In cases where there were more than one SNP from a given gene, weight of literature, linkage characteristics, and potential functionality based on specific location of the SNP within the gene were considered. Gene frequency was also a major selection criterion to ensure adequate power for analysis. For purposes of the analysis examining interactions with PIH reported in this paper, we evaluated SNPs in the following seven genes: eNOS (NOS3), ESR2, VEGF, EDN1, IL-10, HCFXI (KLKB1), IGFR1.

\section{Outcome assessment}

Each participant in the study was required to have undergone a screening mammogram. One of the novel features of this study is the measure of $\% \mathrm{FGV}$ assessed by the method single-energy X-ray absorptiometry (SXA) [17-20]. This method uses a calibration phantom of the same thickness as the compressed breast, circumventing some of the problems associated with other breast density measures including their subjectivity and lack of absolute reference standards [19]. The first generation calibration phantom (Gamma) used for this method has provided preliminary data on 8,600 women to show that $\% \mathrm{FGV}$ is reproducible to approximately $2 \%$ between successive measures and accurate to known standards of breast composition using reference phantoms [17]. Investigators have demonstrated that $\% \mathrm{FGV}$ is inversely correlated with age, body mass index (BMI), and menopausal status, as expected for a measurement of breast density, and is positively associated with breast cancer risk [20]. \% FGV data are collected by the SFMR at all sites in Marin County which employ digital mammography and are obtained from the SFMR through a cooperative agreement. Data used in this study were obtained using version 6.5 of the SXA software.

The MWS was approved by the participating institutions, and participants provided written informed consent for participation in the study.

\section{Statistical analysis}

Multivariable linear regression analyses were conducted to examine the associations between \%FGV and reproductive factors, controlling for relevant confounders. Robust regression techniques were used to minimize the effects of outliers and influential observations (i.e., observations that have a large impact on the regression analysis). All models controlled for a base set of confounding variables, including current age, BMI, race, education, smoking, family history of breast cancer (whether a first degree relative has been diagnosed with breast cancer), hysterectomy status, menopausal status, and exogenous hormone use at the time of the mammogram. Prior to regression, \%FGV was square root transformed to normalize the distribution.

All genotyping data were checked for compliance of single-gene allelic frequencies with Hardy-Weinberg frequency expectations using $\chi^{2}$ goodness-of-fit test. Bivariate associations between the genotypes of the SNPs and $\%$ FGV were examined. Multivariable linear regression models were constructed adjusting for potential confounders including current BMI, age, race, and age of first live birth, and interaction terms were generated for the genotype of each SNP compared to a baseline genotype. Statistical tests were conducted to examine the interaction term for each level of the SNP compared to the baseline level of the SNP, as well as for the joint interaction effect of each SNP overall and PIH, and $p$ values examined for statistical significance. 


\section{Results}

The distribution of covariates and the mean $\% \mathrm{FGV}$ for each level of the covariate are presented in Table 1 . The vast majority of the women were White, had a college degree, and were postmenopausal. The mean $\% \mathrm{FGV}$ was 35.3. In these unadjusted analyses, there were significant associations between \%FGV and age, menopausal status, BMI, race, education, smoking status, hysterectomy status, and age at menarche; all associations were in the expected directions.

The distribution of reproductive characteristics and the mean $\%$ FGV for the different levels of the characteristics is presented in Table 2. In this population, $47.9 \%$ gave birth for the first time at age 30 or older and $23 \%$ had only one birth. There were significant crude associations between $\%$ FGV and months of breast-feeding, parity, age at first birth, birthweight, and PIH.

Table 3 presents the results of multivariable models examining the effect of first birth characteristics on breast density overall and stratified by age at first birth. Because the results are presented in units corresponding to the square root transformation of $\% \mathrm{FGV}$, the point estimates are not interpretable on a $\% \mathrm{FGV}$ scale, but can be interpreted in terms of the magnitude of the effect.

Overall, having experienced high blood pressure during the first pregnancy was associated with a significantly lower \%FGV $(-0.31 ; 95 \% \mathrm{CI}-0.52,-0.11)$. In addition, each month of breast-feeding was associated with a significantly increased \%FGV $(0.01 ; 95 \%$ CI 0.003, 0.02). Late menarche (age $15+$ vs. before age 10) was associated with a borderline significant increase in \%FGV $(0.26 ; 95 \% \mathrm{CI}-0.04$, 0.56). This model explained $49 \%$ of the variance in $\% \mathrm{FGV}$.

Models were stratified by whether the first birth occurred before age 30 or at age 30 or later to examine whether these associations varied by age at first birth (Table 3). Among women with a first birth before age 30 , each month of breast-feeding was borderline significantly associated with an increase in breast density $(0.01 ; 95 \%$ CI 0.0002 , 0.03). In addition, having had a low birthweight infant was associated with a borderline significantly decrease in \%FGV (-0.29; $95 \%$ CI $-0.57,0.002)$, and having had a late menarche was associated with a borderline significant increase in \%FGV $(0.32 ; 95 \% \mathrm{CI}-0.05,0.69)$. In women whose first birth occurred at age 30 or later, the model estimates were similar to those in the overall population. Having experienced high blood pressure during the first pregnancy was associated with a significant decrease in $\%$ FGV $(-0.42 ; 95 \% \mathrm{CI}-0.71,-0.13)$, and months of breast-feeding were associated with a significant increase in \%FGV $(0.01 ; 95 \%$ CI $0.001,0.02)$. While the model explained $44 \%$ of the variance in $\% \mathrm{FGV}$ in women whose first birth was age 30 or greater, it explained $38 \%$ of the variability in women whose first birth was age $<30$ years.
Table 1 Mean percent fibroglandular volume (\%FGV) by study population characteristics (Study 1)

\begin{tabular}{|c|c|c|}
\hline \multirow[t]{2}{*}{ Characteristic } & \multicolumn{2}{|c|}{ Parous women $(n=2,440)$} \\
\hline & $n$ & $\begin{array}{l}\text { Mean \%FGV } \\
\text { (SD) }\end{array}$ \\
\hline All women & 2,440 & $35.3(21.0)$ \\
\hline \multicolumn{3}{|l|}{ Age } \\
\hline$\leq 45$ & 481 & $49.4(22.5)$ \\
\hline $46-55$ & 756 & $39.1(22.00)$ \\
\hline $56-65$ & 680 & $28.4(16.0)$ \\
\hline$>65$ & 523 & $25.8(14.2)$ \\
\hline$F$ statistic, $p$ value & & $169.71, p<0.001$ \\
\hline \multicolumn{3}{|l|}{ Menopausal status } \\
\hline Premenopausal & 940 & $46.3(22.7)$ \\
\hline Postmenopausal & 1,500 & $28.4(16.4)$ \\
\hline$F$ statistic, $p$ value & & $509.2, p<0.001$ \\
\hline \multicolumn{3}{|l|}{ Current exogenous hormone use } \\
\hline No & 2,042 & $35.4(21.4)$ \\
\hline Yes & 398 & $34.9(18.8)$ \\
\hline$F$ statistic, $p$ value & & $0.18, p=0.67$ \\
\hline \multicolumn{3}{|l|}{ Body mass index (BMI) } \\
\hline Underweight $(<18.5)$ & 56 & $62.6(25.9)$ \\
\hline Normal weight (18.5-24.9) & 1,525 & $42.3(20.5)$ \\
\hline Overweight (25-29.9) & 578 & $23.2(11.6)$ \\
\hline Obese $(30+)$ & 260 & $16.4(9.0)$ \\
\hline$F$ statistic, $p$ value & & $305.45, p<0.001$ \\
\hline \multicolumn{3}{|l|}{ Race } \\
\hline White & 2,214 & $35.1(21.00)$ \\
\hline Black & 9 & $32.3(25.3)$ \\
\hline Asian & 96 & $40.4(21.6)$ \\
\hline Other & 41 & $41.9(23.2)$ \\
\hline Hispanic & 80 & $31.6(16.5)$ \\
\hline$F$ statistic, $p$ value & & $3.13, p=0.01$ \\
\hline \multicolumn{3}{|l|}{ Education } \\
\hline HS or less & 109 & $28.1(17.1)$ \\
\hline Some college & 614 & $29.7(17.1)$ \\
\hline College or post graduate & 1,717 & $37.8(21.9)$ \\
\hline$F$ statistic, $p$ value & & $41.80, p<0.001$ \\
\hline \multicolumn{3}{|l|}{ Smoking History } \\
\hline Never & 1,383 & $37.7(21.9)$ \\
\hline Current & 74 & $32.00(18.1)$ \\
\hline Former & 983 & $32.1(19.3)$ \\
\hline$F$ statistic, $p$ value & & $21.81, p<0.001$ \\
\hline \multicolumn{3}{|l|}{ Hysterectomy status } \\
\hline No & 2,192 & $36.3(21.2)$ \\
\hline Yes & 248 & $26.8(17.1)$ \\
\hline$F$ statistic, $p$ value & & $46.41, p<0.001$ \\
\hline \multicolumn{3}{|l|}{ Menarche } \\
\hline 10 or younger & 93 & $29.8(19.3)$ \\
\hline $11-14$ & 2,089 & 34.7 (20.6) \\
\hline $15+$ & 258 & $41.8(22.8)$ \\
\hline$F$ statistic, $p$ value & & $16.72, p<0.001$ \\
\hline
\end{tabular}


Table 2 Mean percent fibroglandular volume (\%FGV) by first pregnancy risk factors (Study 1)

\begin{tabular}{|c|c|c|}
\hline \multirow[t]{2}{*}{ Characteristic } & \multicolumn{2}{|c|}{ Parous women $(n=2,440)$} \\
\hline & $n$ & Mean \%FGV (SD) \\
\hline \multicolumn{3}{|c|}{ Months of breast-feeding } \\
\hline 0 & 460 & $27.2(15.4)$ \\
\hline $1-3$ & 434 & $32.4(18.7)$ \\
\hline $4-6$ & 547 & $35.2(20.9)$ \\
\hline $7-12$ & 666 & $39.1(21.9)$ \\
\hline$>12$ & 333 & $42.9(24.1)$ \\
\hline$F, p$ & & $37.72, p<0.001$ \\
\hline \multicolumn{3}{|l|}{ Parity } \\
\hline 1 & 563 & $36.8(22.5)$ \\
\hline 2 & 1,219 & $36.1(21.0)$ \\
\hline 3 & 482 & $34.0(19.7)$ \\
\hline 4 & 142 & $29.0(17.5)$ \\
\hline $5+$ & 34 & $25.6(16.5)$ \\
\hline$F, p$ & & $6.66, p<0.001$ \\
\hline \multicolumn{3}{|l|}{ Age at first birth } \\
\hline$<20$ & 110 & $25.9(17.0)$ \\
\hline $20-29$ & 1,161 & $30.8(18.1)$ \\
\hline $30-34$ & 680 & $39.5(21.7)$ \\
\hline $35+$ & 489 & $42.2(23.6)$ \\
\hline$F, p$ & & $55.37, p<0.001$ \\
\hline \multicolumn{3}{|l|}{ Birthweight } \\
\hline Low & 178 & $33.1(20.2)$ \\
\hline High & 262 & $32.1(19.5)$ \\
\hline Normal & 2,000 & $35.9(21.2)$ \\
\hline$F, p$ & & $4.84, p=0.01$ \\
\hline \multicolumn{3}{|c|}{ Pregnancy high blood pressure } \\
\hline No & 2,284 & $35.6(21.0)$ \\
\hline Yes & 156 & $30.9(19.8)$ \\
\hline$F, p$ & & $7.21, p=0.01$ \\
\hline \multicolumn{3}{|l|}{ Weeks gestation } \\
\hline $38+$ & 2,227 & $35.3(21.1)$ \\
\hline $36-37$ & 156 & $36.4(20.7)$ \\
\hline$\leq 35$ & 57 & $32.00(18.3)$ \\
\hline$F, p$ & & $0.92, p=0.40$ \\
\hline \multicolumn{3}{|c|}{ Pregnancy weight gain (lbs) } \\
\hline 0 or weight loss & 5 & $20.8(13.9)$ \\
\hline $1-10$ & 50 & $35.0(21.3)$ \\
\hline $11-25$ & 912 & $35.2(21.1)$ \\
\hline $26-40$ & 1,064 & $35.3(20.7)$ \\
\hline$>40$ & 409 & $35.8(21.5)$ \\
\hline$F, p$ & & $0.65, p=0.62$ \\
\hline
\end{tabular}

Because of the significant protective associations between $\mathrm{PIH}$ and \%FGV, and the consistency of this finding with those in the literature indicating a significantly protective effect of $\mathrm{PIH}$ on breast cancer, we analyzed salivary DNA samples to determine whether interactions existed for the associations between PIH and \%FGV based on seven SNPs previously shown to be associated with PIH (Online Resource 1). For this analysis, participants were excluded if they had a history of breast cancer or use of antiestrogens, if they did not have a valid \%FGV measurement, or if they had never had a live birth, leaving an analysis sample size of 1,240, which was further reduced in multivariable models because of missing data on one or more of the variables included in the model, including SNP results when genotyping was not successful for that SNP. In line with the Study 1 analysis that was limited to reproductive characteristics in the first pregnancy, our Study 2 definition for the exposure was limited to the development of PIH in first pregnancy. All of the seven SNPs were found to be in compliance with Hardy-Weinberg frequency expectations. In this Study 2 subset, \%FGV was lower in women with a history of $\mathrm{PIH}$, although this finding did not reach statistical significance. None of the bivariate associations between the genotypes of the seven selected SNPs and \%FGV were statistically significant.

Multivariable analyses indicated no significant interactions between PIH and five of the seven SNPs tested (Table 4); however, two of the seven SNPs were associated with PIH. A borderline significant interaction was found between the CT genotype of the VEGF SNP and PIH on $\%$ FGV ( $p=0.063$ ) (compared to the CC genotype). The TT genotype, which has the lowest frequency, did not occur in any of the women with PIH in the first pregnancy and thus does not appear in the results. Statistically significant interactions were found between PIH and the GT genotype of the IGFR1 SNP ( $p=0.01)$ (compared to the GG genotype); those with PIH and the GT genotype had significantly lower $\%$ FGV than those with GG genotype of the IGFR1 SNP (joint interaction term $p$ value $=0.03$ ). A borderline significant interaction was found between the TT genotype of the IGFR1 SNP and \%FGV (compared to the GG genotype) ( $p=0.07$ ). This group was only half the size of the GT group, which may explain why, despite the apparent larger effect seen in the graphic, this did not reach statistical significance. The main effects terms for the GT and TT genotypes of the IGFR1 SNP were both 0.18 in this multivariable model that included the interaction terms. Both of these sets of interactions are presented visually in Figs. 1 and 2, below.

In this case, it can be seen that having $\mathrm{PIH}$ and the $\mathrm{CC}$ genotype resulted in no change in $\% \mathrm{FGV}$, while having $\mathrm{PIH}$ with the CT genotype resulted in a decrease in \%FGV.

\section{Discussion}

In this cross-sectional study, we found that PIH during first pregnancy was associated with significantly reduced breast density measured by $\% \mathrm{FGV}$ in later life, the effect of which was greatest in those women whose first birth 
Table 3 Linear regression model: percent fibroglandular volume (\%FGV) in parous MWS women with \%FGV measurement and model variables (Study 1)

\begin{tabular}{|c|c|c|c|}
\hline & \multirow{2}{*}{ Overall $(n=2,440)$} & \multicolumn{2}{|l|}{ Age at first birth } \\
\hline & & $<30(n=1,271)$ & $30+(n=1,169)$ \\
\hline Parity (number: $1-5$ ) & $0.02(-0.04,0.08)$ & $0.01(-0.06,0.08)$ & $-0.05(-0.16,0.07)$ \\
\hline High blood pressure (vs. no) & $-0.31(-0.52,-0.11)^{*}$ & $-0.24(-0.53,0.06)$ & $-0.42(-0.71,-0.13)^{*}$ \\
\hline Breast-feeding (months) & $0.01(0.003,0.02)^{*}$ & $0.01(0.0002,0.03)^{\dagger}$ & $0.01(0.001,0.02)^{*}$ \\
\hline Gestational weight gain (lbs) & $-0.002(-0.01,0.002)$ & $-0.0001(-0.01,0.01)$ & $-0.002(-0.01,0.01)$ \\
\hline \multicolumn{4}{|l|}{ Birthweight (vs. normal) } \\
\hline Low & $-0.04(-0.26,0.18)$ & $-0.29(-0.57,0.002)^{\dagger}$ & $0.05(-0.31,0.40)$ \\
\hline High & $-0.04(-0.21,0.12)$ & $0.01(-0.21,0.22)$ & $-0.02(-0.28,0.23)$ \\
\hline \multicolumn{4}{|c|}{ Weeks gestation (versus $38+$ weeks) } \\
\hline 36-37 weeks & $0.08(-0.14,0.29)$ & $0.24(-0.05,0.54)$ & $0.03(-0.28,0.35)$ \\
\hline$<35$ weeks & $-0.02(-0.40,0.35)$ & $0.23(-0.29,0.76)$ & $-0.002(-0.55,0.54)$ \\
\hline \multicolumn{4}{|l|}{ Menarche (vs. <10) } \\
\hline $11-14$ & $0.07(-0.19,0.33)$ & $0.07(-0.24,0.39)$ & $-0.08(-0.52,0.37)$ \\
\hline $15+$ & $0.26(-0.04,0.56)^{\dagger}$ & $0.32(-0.05,0.69)^{\dagger}$ & $-0.04(-0.54,0.47)$ \\
\hline \multicolumn{4}{|l|}{ Age at first birth (vs. $<20$ ) } \\
\hline $20-29$ & $-0.01(-0.26,0.24)$ & NA & NA \\
\hline $30-34$ & $0.01(-0.26,0.28)$ & & \\
\hline $35+$ & $0.13(-0.15,0.41)$ & & \\
\hline$R^{2}$ & 0.49 & 0.38 & 0.44 \\
\hline
\end{tabular}

Controlled for current age, BMI, race, education, smoking, first degree relative with breast cancer, hysterectomy status, menopausal status (except in models stratified by hysterectomy status), and hormone use at the time of the mammogram

* Differences significant at the $p<0.05$ level

$\dagger$ Differences significant at the $p<0.10$ level

occurred at age 30 or later, where preeclampsia and gestational hypertension (or PIH) are more prevalent. To our knowledge, this is the first study to identify an association between experience of a pregnancy affected by PIH/gestational hypertension and \%FGV. PIH has been fairly consistently associated with a reduction in breast cancer risk (e.g., $[5,21])$, though some studies have found no (e.g., $[6,22])$ or even increased risk [23, 24]. PIH is a multifactorial disease with genetic and environmental factors known to be involved in its etiology although full understanding of its pathogenesis remains elusive despite decades of research [25]. Likewise, the mechanism by which PIH affects breast cancer risk is unknown although potentially via the same etiologic basis as PIH, with theories focusing on placental dysfunction and a subsequent lowering of circulating estrogens [26], increase in serum insulin-like growth factor [27], and/or angiogenic factors [28]. In support of the theory of an altered hormonal milieu are findings such as those of Cerhan et al. [29] who found non-significantly reduced breast density in women born from a pregnancy in which their mothers experienced eclampsia/preeclampsia [29], and similar findings reported in a systematic review by Xue and Michels [30] who found significantly decreased risk of breast cancer if a woman's mother had experienced preeclampsia or eclampsia.

In this study, PIH was shown to significantly interact with specific allelic variants of insulin growth factor receptor-1 (IGFR1; rs2016347), and borderline significantly with a specific allelic variant of vascular endothelial growth factor-A (VEGF-A; rs3025039) genes, indicating that the protective effects of first pregnancy PIH on later life breast density and breast cancer risk may depend on inherited functional variants in these two growth factor receptor and angiogenic factor genes. Prior studies involving these allelic variants support this conclusion, since the VEGF-A SNP investigated (rs3025039) has been repeatedly linked to decreased plasma levels of VEGF and reduced breast cancer risk, [31-33] while the IGFR1 SNP investigated (rs2016347) has not only been previously associated with breast density but also found to be an independent prognostic marker for breast cancer recurrence $[34,35])$. While these various sources of evidence make it unlikely that these two SNPs found to modulate the significant association between PIH and \%FGV were simply false positive discoveries, these novel observations require additional validation in larger population-based studies 
Table 4 Multivariate

associations between genotypes of the 7 PIH SNPs and percent fibroglandular volume (\%FGV) (Study 2)

\begin{tabular}{|c|c|c|c|c|c|c|}
\hline SNP & $\begin{array}{l}\text { Baseline } \\
\text { genotype }\end{array}$ & Interaction term & Estimate & $p$ value & $\begin{array}{l}\text { Joint test } p \text { values for } \\
\text { interaction }\end{array}$ & $\begin{array}{l}n \text { For each } \\
\text { genotype }\end{array}$ \\
\hline \multirow[t]{3}{*}{ EDN } & GG & & & & & 471 \\
\hline & & EDN_GT $\times$ PIH & -0.178 & 0.58 & & 266 \\
\hline & & EDN_TT $\times$ PIH & 0.300 & 0.70 & 0.77 & 38 \\
\hline \multirow[t]{3}{*}{ HCFX } & $\mathrm{CC}$ & & & & & 374 \\
\hline & & HCFX_CT $\times$ PIH & -0.004 & 0.99 & & 323 \\
\hline & & HCFZ_TT $\times$ PIH & -0.263 & 0.57 & 0.84 & 75 \\
\hline \multirow[t]{3}{*}{ NOS3 } & $\mathrm{CC}$ & & & & & 124 \\
\hline & & NOS3_CT $\times$ PIH & 0.075 & 0.85 & & 342 \\
\hline & & NOS3_TT $\times$ PIH & 0.176 & 0.68 & 0.91 & 305 \\
\hline \multirow[t]{3}{*}{ IL10 } & $\mathrm{CC}$ & & & & & 186 \\
\hline & & IL10_CT $\times$ PIH & -0.020 & 0.95 & & 365 \\
\hline & & IL10_TT $\times$ PIH & -0.116 & 0.76 & 0.95 & 214 \\
\hline \multirow[t]{2}{*}{ VEGF } & $\mathrm{CC}$ & VEGF_CT $\times$ PIH & -0.621 & 0.06 & NA & 557 \\
\hline & & & & & & 200 \\
\hline \multirow[t]{3}{*}{ IGFR1 } & GG & & & & & 174 \\
\hline & & IGFR1_GT $\times$ PIH & -0.906 & 0.01 & & 389 \\
\hline & & IGFR1_TT $\times$ PIH & -0.734 & 0.07 & 0.03 & 195 \\
\hline \multirow[t]{3}{*}{ ESR2 } & $\mathrm{CC}$ & & & & & 131 \\
\hline & & ESR2_CT $\times$ PIH & 0.403 & 0.31 & & 379 \\
\hline & & $\mathrm{ESR} 2 \_\mathrm{TT} \times \mathrm{PIH}$ & -0.053 & 0.90 & 0.60 & 251 \\
\hline
\end{tabular}

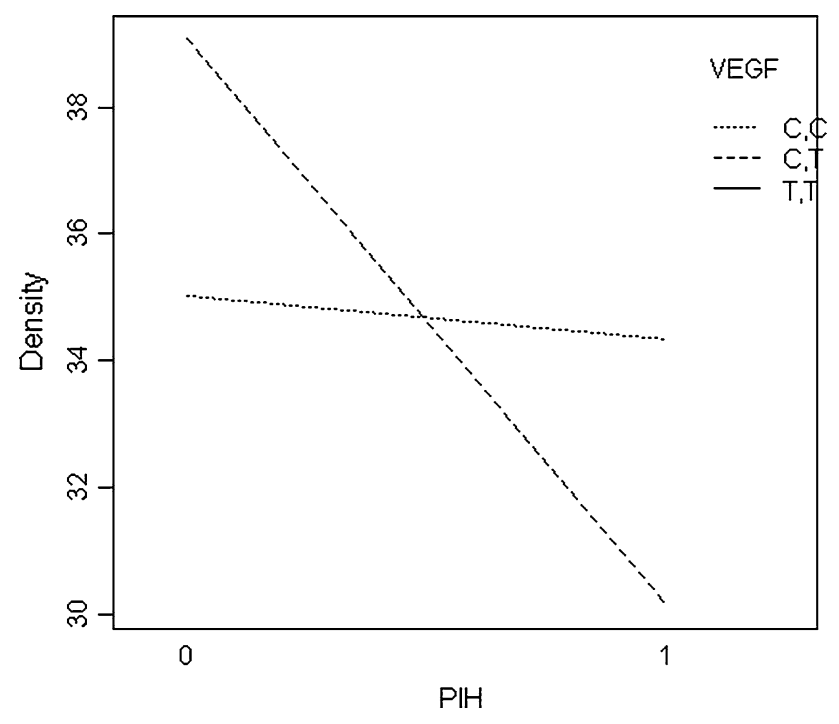

Fig. 1 Interaction of PIH and VEGF

given the strong inheritance pattern underlying breast density.

Duration of breast-feeding in first pregnancy was associated with increased \%FGV later in life in our overall study population and in women regardless of age at first birth (though these findings were of borderline significance). Our finding of a positive association between

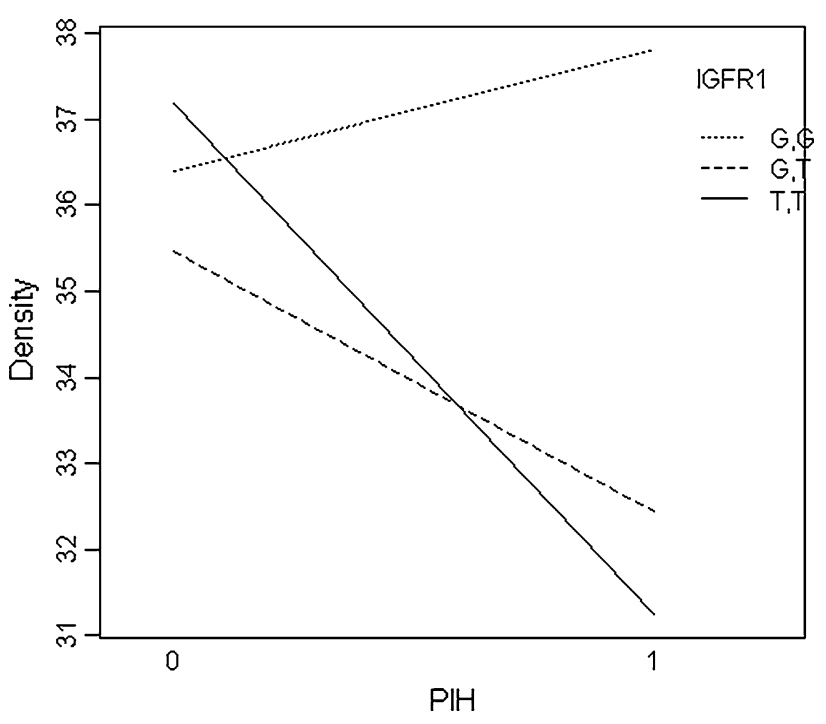

Fig. 2 Interaction of PIH and IGFR1

duration of breast-feeding and $\% \mathrm{FGV}$ is in agreement with that of Lope et al. [14], who found a positive association between breast density (using the cumulus method) and duration of lactation, but conflicts with those of others who found no association (e.g., $[10,25])$ or an inverse association between breast-feeding and breast density (e.g., [36]). Differences in the timing and measurement of breast 
density between these diverse studies are the most likely explanation for their disparate associations, though this could also be due to basic differences in the study populations. Although breast-feeding has been thought to produce an overall protective effect against breast cancer (e.g., [37]), many studies find no association (e.g., [22]) and recent systematic reviews of the topic fail to support an association (e.g., [38, 39]). More research is needed in the area of breast-feeding and breast health to better elucidate whether a protective effect exists, and if so, when and how breast-feeding might affect breast density.

A number of other first pregnancy factors were less consistently associated with $\% \mathrm{FGV}$, but were suggestive in certain sub-analyses, including gestational weight gain, infant birthweight, and preterm birth. Other authors have found associations between breast density and birthweight $[11,14]$ and preterm birth and breast density [11]. While our data were suggestive of relationships between \%FGV and these birth characteristics, our findings were neither consistent nor strong. The differences may be due to differences in the breast density measure or characteristics of the study populations, including differences in the age structure (only 55 and younger in El-Bastawissi et al. [11] and 45-68 in Lope et al. [14]).

This study has a number of important strengths, including a large sample size, a contemporary sample, a novel measure of breast density, and the availability of a wide variety of reproductive characteristics for study. The primary limitation in this study is the use of self-reported data for reproductive history. Though it is possible that women may not accurately recall information about their first pregnancy, particularly if it occurred in the distant past, we would expect that they would accurately recall the major events including their age, an experience of PIH, and breast-feeding. To the extent that recall bias is present, it would be nondifferential (i.e., not associated with \%FGV), and would thus bias the results toward the null. Another limitation is that, despite the fact that the overall sample size in this study was large, the sample size was small for specific subgroup analyses. Studies with larger populations may be better able to detect significant associations between birth characteristics and breast density where they exist. Selection bias may be present in the sample of patients providing saliva samples for the SNP analyses; women who consented to donate saliva were significantly more likely to be of White Non-Hispanic race and to be of higher socioeconomic status based on education and income, but were not significantly different in terms of family history of breast cancer or current age. While this may limit the generalizability of the findings indicating an interaction between PIH and VEGF and IGFR1 on \%FGV, any selection bias present should not limit the validity of the findings. Finally, this study was intentionally restricted to first births, but it will be important to determine whether the findings for first birth characteristics hold for all births or whether they are unique to the first birth (e.g., whether total duration of breastfeeding has the same association with breast density as duration of breast-feeding after the first birth).

\section{Conclusion}

In summary, we found associations between first birth characteristics and breast density measured as \%FGV that confirmed and extended the few published findings on birth characteristics and breast density. PIH was associated with a decrease in breast density and breast-feeding an increase in breast density, which may help elucidate the pathway by which they operate to affect breast cancer. Variation in the association between PIH and \%FGV by genotype of IGFR 1 and VEGF suggest that the protective effect of PIH on breast density may vary between women depending on genotype.

Acknowledgments This work was supported by Supported by CDC Grant No. 5H75 DP001730-2 and The Avon Foundation Grant No. 02-2009-053. Data collection for the San Francisco Mammography Registry and Drs. Karla Kerlikowske and John Shepherd was supported, in part, by NCI-funded grants U01 CA63740 and P01 CA154292. We would like to thank the MWS Steering Committee for their work on the design and conduct of the MWS, and the study sites and residents of Marin County for their support of, and participation in, this research. We would also like to thank Rachel Puckett for her work in processing the saliva samples.

Conflict of interest The authors declare that they have no conflict of interest.

Open Access This article is distributed under the terms of the Creative Commons Attribution License which permits any use, distribution, and reproduction in any medium, provided the original author(s) and the source are credited.

\section{References}

1. Lambe M, Hsieh CC, Chan HW, Ekbom A, Trichopoulos D, Adami HO (1996) Parity, age at first and last birth, and risk of breast cancer: a population-based study in Sweden. Breast Cancer Res Treat 38(3):305-311

2. Britt K, Ashworth A, Smalley M (2007) Pregnancy and the risk of breast cancer. Endocr Relat Cancer 14(4):907-933. doi:10.1677/ ERC-07-0137

3. Innes KE, Byers TE (2004) First pregnancy characteristics and subsequent breast cancer risk among young women. Int J Cancer 112(2):306-311. doi:10.1002/ijc. 20402

4. Wohlfahrt J, Melbye M (1999) Maternal risk of breast cancer and birth characteristics of offspring by time since birth. Epidemiology 10(4):441-444. doi:10.1097/00001648-199907000-00017

5. Opdahl S, Romundstad PR, Alsaker MD, Vatten LJ (2012) Hypertensive diseases in pregnancy and breast cancer risk. Br J Cancer 107(1):176-182. doi:10.1038/bjc.2012.195

6. Cnattingius S, Torrang A, Ekbom A, Granath F, Petersson G, Lambe M (2005) Pregnancy characteristics and maternal risk of 
breast cancer. JAMA 294(19):2474-2480. doi:10.1001/jama.294. 19.2474

7. Brasky TM, Li Y, Jaworowicz DJ Jr, Potischman N, Ambrosone CB, Hutson AD, Nie J, Shields PG, Trevisan M, Rudra CB, Edge SB, Freudenheim JL (2013) Pregnancy-related characteristics and breast cancer risk. Cancer Causes Control 24(9):1675-1685. doi:10.1007/s10552-013-0242-9

8. Troisi R, Weiss HA, Hoover RN, Potischman N, Swanson CA, Brogan DR, Coates RJ, Gammon MD, Malone KE, Daling JR, Brinton LA (1998) Pregnancy characteristics and maternal risk of breast cancer. Epidemiology 9(6):641-647. doi:10.1097/ 00001648-199811000-00014

9. van Gils CH, Hendriks JH, Holland R, Karssemeijer N, Otten JD, Straatman H, Verbeek AL (1999) Changes in mammographic breast density and concomitant changes in breast cancer risk. Eur J Cancer Prev 8(6):509-515

10. Butler LM, Gold EB, Greendale GA, Crandall CJ, Modugno F, Oestreicher N, Quesenberry CP Jr, Habel LA (2008) Menstrual and reproductive factors in relation to mammographic density: the Study of Women's Health Across the Nation (SWAN). Breast Cancer Res Treat 112(1):165-174. doi:10.1007/s10549-0079840-0

11. El-Bastawissi AY, Aiello EJ, Buist DS, Taplin SH (2005) Previous pregnancy outcome and breast density (United States). Cancer Causes Control 16(4):407-417. doi:10.1007/s10552-0045027-8

12. Titus-Ernstoff L, Tosteson AN, Kasales C, Weiss J, Goodrich M, Hatch EE, Carney PA (2006) Breast cancer risk factors in relation to breast density (United States). Cancer Causes Control 17(10):1281-1290. doi:10.1007/s10552-006-0071-1

13. El-Bastawissi AY, White E, Mandelson MT, Taplin SH (2000) Reproductive and hormonal factors associated with mammographic breast density by age (United States). Cancer Causes Control 11(10):955-963

14. Lope V, Perez-Gomez B, Sanchez-Contador C, Santamarina MC, Moreo P, Vidal C, Laso MS, Ederra M, Pedraz-Pingarron C, Gonzalez-Roman I, Garcia-Lopez M, Salas-Trejo D, Peris M, Moreno MP, Vazquez-Carrete JA, Collado F, Aragones N, Pollan M (2012) Obstetric history and mammographic density: a population-based cross-sectional study in Spain (DDM-Spain). Breast Cancer Res Treat 132(3):1137-1146. doi:10.1007/s10549-0111936-x

15. Diergaarde B, Potter JD, Jupe ER, Manjeshwar S, Shimasaki CD, Pugh TW, Defreese DC, Gramling BA, Evans I, White E (2008) Polymorphisms in genes involved in sex hormone metabolism, estrogen plus progestin hormone therapy use, and risk of postmenopausal breast cancer. Cancer Epidemiol Biomarkers Prev 17(7):1751-1759. doi:10.1158/1055-9965.EPI-08-0168

16. Dalessandri KM, Miike R, Wrensch MR, Wiencke JK, Farren G, Pugh TW, Manjeshwar S, Benz CC, Jupe ER (2009) Breast cancer risk assessment in the high risk Marin County population using OncoVue compared to SNPs from genome-wide association studies. Paper presented at the San Antonio Breast Cancer Symposium, 11 December 2009. San Antonio, TX, 11 December 2009

17. Malkov S, Wang J, Kerlikowske K, Cummings SR, Shepherd JA (2009) Single X-ray absorptiometry method for the quantitative mammographic measure of fibroglandular tissue volume. Med Phys 36(12):5525-5536

18. Malkov S, Wang J, Shepherd J (2008) Improvements to single energy absorptiometry method for digital mammography to quantify breast tissue density. In: Krupinski E (ed) 9th International workshop on digital mammography. IWDM 2008. Proceedings of the digital mammography 9th international workshop. Springer, Berlin, pp 1-8
19. Shepherd JA, Herve L, Landau J, Fan B, Kerlikowske K, Cummings SR (2005) Novel use of single X-ray absorptiometry for measuring breast density. Technol Cancer Res Treat 4(2):173-182

20. Shepherd JA, Kerlikowske K, Ma L, Duewer F, Fan B, Wang J, Malkov S, Vittinghoff E, Cummings SR (2011) Volume of mammographic density and risk of breast cancer. Cancer Epidemiol Biomarkers Prev 20(7):1473-1482. doi:10.1158/10559965.EPI-10-1150

21. Terry MB, Perrin M, Salafia CM, Zhang FF, Neugut AI, Teitelbaum SL, Britton J, Gammon MD (2007) Preeclampsia, pregnancy-related hypertension, and breast cancer risk. Am J Epidemiol 165(9):1007-1014. doi:10.1093/aje/kwk105

22. Ma H, Henderson KD, Sullivan-Halley J, Duan L, Marshall SF, Ursin G, Horn-Ross PL, Largent J, Deapen DM, Lacey JV Jr, Bernstein L (2010) Pregnancy-related factors and the risk of breast carcinoma in situ and invasive breast cancer among postmenopausal women in the California Teachers Study cohort. Breast Cancer Res 12(3):R35. doi:10.1186/bcr2589

23. Calderon-Margalit R, Friedlander Y, Yanetz R, Deutsch L, Perrin MC, Kleinhaus K, Tiram E, Harlap S, Paltiel O (2009) Preeclampsia and subsequent risk of cancer: update from the Jerusalem Perinatal Study. Am J Obstet Gynecol 200(1):63 e61-63 e65. doi:10.1016/j.ajog.2008.06.057

24. Talamini R, Franceschi S, Favero A, Negri E, Parazzini F, La Vecchia C (1997) Selected medical conditions and risk of breast cancer. Br J Cancer 75(11):1699-1703

25. Modugno F, Ngo DL, Allen GO, Kuller LH, Ness RB, Vogel VG, Costantino JP, Cauley JA (2006) Breast cancer risk factors and mammographic breast density in women over age 70 . Breast Cancer Res Treat 97(2):157-166. doi:10.1007/s10549-005-9105-8

26. Isouard G (1979) Measurement of serum levels of oestriol and human placental lactogen in the management of pre-eclamptic pregnancies. Med J Aust 2(8):401-404

27. Altinkaynak K, Aksoy HH, Bakan E, Kumtepe Y (2003) Serum IGF-I and IGFBP-3 in healthy pregnancies and patients with preeclampsia. Clin Biochem 36(3):221-223. doi:10.1016/S00099120(03)00008-0

28. Vatten LJ, Romundstad PR, Jenum PA, Eskild A (2009) Angiogenic balance in pregnancy and subsequent breast cancer risk and survival: a population study. Cancer Epidemiol Biomarkers Prev 18(7):2074-2078. doi:10.1158/1055-9965.EPI-09-0207

29. Cerhan JR, Sellers TA, Janney CA, Pankratz VS, Brandt KR, Vachon CM (2005) Prenatal and perinatal correlates of adult mammographic breast density. Cancer Epidemiol Biomarkers Prev 14(6):1502-1508. doi:10.1158/1055-9965.EPI-04-0762

30. Xue F, Michels KB (2007) Intrauterine factors and risk of breast cancer: a systematic review and meta-analysis of current evidence. Lancet Oncol 8(12):1088-1100. doi:10.1016/S14702045(07)70377-7

31. Al-Habboubi HH, Sater MS, Almawi AW, Al-Khateeb GM, Almawi WY (2011) Contribution of VEGF polymorphisms to variation in VEGF serum levels in a healthy population. Eur Cytokine Netw 22(3):154-158. doi:10.1684/ecn.2011.0289

32. Renner W, Kotschan S, Hoffmann C, Obermayer-Pietsch B, Pilger E (2000) A common $936 \mathrm{C} / \mathrm{T}$ mutation in the gene for vascular endothelial growth factor is associated with vascular endothelial growth factor plasma levels. J Vasc Res 37(6): 443-448

33. Sa-nguanraksa D, O-charoenrat P (2012) The role of vascular endothelial growth factor a polymorphisms in breast cancer. Int $\mathbf{J}$ Mol Sci 13(11):14845-14864. doi:10.3390/ijms131114845

34. Biong M, Gram IT, Brill I, Johansen F, Solvang HK, Alnaes GI, Fagerheim T, Bremnes Y, Chanock SJ, Burdett L, Yeager M, Ursin G, Kristensen VN (2010) Genotypes and haplotypes in the insulin-like growth factors, their receptors and binding proteins in 
relation to plasma metabolic levels and mammographic density. BMC Med Genomics 3:9. doi:10.1186/1755-8794-3-9

35. Lenz H-J, Stebbing J (2012) IGF1R polymorphism predicts tumor recurrence in breast cancer patients. 20,120,289,424, 15 November 2012

36. Masala G, Ambrogetti D, Assedi M, Giorgi D, Del Turco MR, Palli D (2006) Dietary and lifestyle determinants of mammographic breast density. A longitudinal study in a Mediterranean population. Int J Cancer 118(7):1782-1789. doi:10.1002/ijc.21558

37. Collaborative Group on Hormonal Factors in Breast Cancer (2002) Breast cancer and breastfeeding: collaborative reanalysis of individual data from 47 epidemiological studies in 30 countries, including 50302 women with breast cancer and 96973 women without the disease. Lancet 360(9328):187-195. doi:10. 1016/S0140-6736(02)09454-0

38. Nagata C, Mizoue T, Tanaka K, Tsuji I, Tamakoshi A, Wakai K, Matsuo K, Ito H, Sasazuki S, Inoue M, Tsugane S (2012) Breastfeeding and breast cancer risk: an evaluation based on a systematic review of epidemiologic evidence among the Japanese population. Jpn J Clin Oncol 42(2):124-130. doi:10.1093/jjco/hyr182

39. Yang L, Jacobsen KH (2008) A systematic review of the association between breastfeeding and breast cancer. J Womens Health (Larchmt) 17(10):1635-1645. doi:10.1089/jwh.2008.0917 